\title{
Application of delay integral equations in population growth
}

Fadhel Subhi Fadhel*

Date of acceptance $3 / 7 / 2008$

Thekra Abdul Latiff**

\begin{abstract}
:
In this paper, the delay integral equations in population growth will be described,discussed, studied and transfered this model to integro-differential equation. At last,we will solve this problem by using variational approach.
\end{abstract}

Key words: delay integral equations, calculus of variation

\section{Introduction:-}

Amain part of applied mathematics specification by trying describe change something in relation to time .

Although the communities of human,animals and plants are growing but in some cases decreasing relative to time.

Therefore, the ability to forecasting the size of commuity future wise according to present and past charts is something preferable,[1].

The study of population growth includes the forecasting of any future surge in birth rates, which is of great importance for future planning throughout the world,[2].

Many models of population growth have been proposed both with and without time lags, [3].

A special class is represented by the differential equations with affine modification of the argument which can be delay differential equation or differential equations with linear modification of the argu ment .Many results concerning these equations are given in the paper[4].

Therefore, in this paper we will construct the model of population growth dependent on past values.

\section{Description of the model of population growth:-}

We will construct the model of population growth with time lag.

Suppose that the biological selfregulatory reaction represent by the factor $\left[1-\frac{N(t)}{p}\right]$

in differential equation :-

$\frac{d N(t)}{d t}=K\left[1-\frac{N(t)}{p}\right] N(t) \ldots \ldots .(1)$

not instantaneous, but responds only after sometime lag $r>0$.

Then,instead of (1)we have the delay differential equation:-

$$
\frac{d N(t)}{d t}=K\left[1-\frac{N(t-r)}{p}\right] N(t) .
$$

This equation had been studied extensively by Wrigh in 1945,1955 ,Kakutani and Warkus in 1958, Jones in 1962,Kaplan and Yorke in 1975 and others,[3].

We can notice that ,equation (2)is anon-linear delay differential equation, and hence the integral equation with be non-linear.

We will take another model of population growth which have linear integral equation and operator of this equation will be al so linear.

Let $\mathrm{N}(\mathrm{t})$ to denotes the number of individuals in a population at time

*Department of Mathematics, College of Science,Al-Nahrin University.

**Deprartment of Mathematics, College of Science for Women,Baghdad University. 
$t$,and let us suppose that every member of the population has a life time $t$.

Now, let us assume that the number of births per unit time is a function of $\mathrm{N}(\mathrm{t})$

only, namlay $g_{1(u)}$ at time $\mathrm{t}$ and $g_{2(u)}$ at time $\mathrm{t}-\tau$.

Then,We have the simples model of population growth:

$$
\frac{d N(t)}{d t}=g_{1}(N(t))-g_{2}(N(t-\tau)) \ldots
$$

Where $g_{1}$ and $g_{2}$ are given continous positive functions and $\tau$ is the life time of members of the species. [5].

\section{The Main Result:}

\section{Integral equation formulation for the model of population growth:-}

This section is divided into three sub section, integral formulation ,variational formulation and the numerical solution of the model of population growth

We will transfer equation (3)which represent the model of population growth with time lag to an integral equation with time lag by the following:-

We can make the model of population growth with delay, which is represented by equation (3) more realistic by assuming that the number of death per unit time at time $t$ is :

$$
\begin{gathered}
g_{2}(\mathrm{~N}(\mathrm{t}-\tau))=-\int_{0}^{\tau} g_{2}(\mathrm{~N}(\mathrm{t}-\mathrm{s})) b^{*}(\mathrm{~s}) \mathrm{ds} \\
\text { for } 0 \leq \mathrm{t} \leq \tau \ldots \ldots . .(4) \\
\text { Where } \mathrm{b}(\mathrm{s}) \text { represents the } \\
\text { probability of survival to age } \mathrm{s} \text {. }
\end{gathered}
$$

As in previous models (3), we can state the following, more complicated relation:

$$
\frac{d N(t)}{d t}=g_{1}(\mathrm{~N}(\mathrm{t}))+\int_{0}^{\tau} g_{2}(\mathrm{~N}(\mathrm{t}-\mathrm{s})) b^{\cdot}(\mathrm{s})
$$

ds , for $0 \leq \mathrm{t} \leq \tau$

This equation which gives a more precise model of population growth which is an integro-differential equation, [5].

\section{The variational formulation of population growth:-}

We will find the variational formulation corresponding to equation (5).

Suppose the continuous positive function $g_{1}(\mathrm{u})$ and $g_{2}(\mathrm{u})$ in (5) are given by:-

$$
g_{1}(\mathrm{u})=u^{2}, \quad g_{2}(\mathrm{u})=\mathrm{u}
$$

Therefore, equation (5) becomes:-

$$
\frac{d N(t)}{d t}=(N(t))^{2}+\int_{0}^{\tau} N(t-s) b^{\bullet}(s) d s
$$

, Where $0 \leq t \leq \tau$

This equation represents the delay intgero-differential equation with the upper limit of integral to be constant .

Define an operator L corresponding to equation (6) of the forme:-

$$
L=\frac{d}{d t}-\int_{0}^{\tau} b^{\bullet}(s) D d s
$$

where $\mathrm{D}$ is the shift operator defined by:-

$\mathrm{DN}(\mathrm{s})=\mathrm{N}(\mathrm{t}-\mathrm{s})$

The operator $\mathrm{L}$ is a linear and symmetric.[6]

Then, by using the theorem :-

"if the given linear operator L is symmetric with respect to the chosen non-degenerat bilinear form $\langle\mathrm{u}, \mathrm{v}\rangle$, the $\mathrm{u}$ is the solution of the equation $\mathrm{Lu}=\mathrm{f}$ if and only if $\mathrm{u}$ is the critical points of the functional :-

$$
\mathrm{F}(\mathrm{u})=\frac{1}{2}<\mathrm{Lu}, \mathrm{u}>-<\mathrm{f}, \mathrm{u}>\text { " }
$$


This is the basic theorem of the theory of the inverse problem of calculus of variation .[7].

The solution of equation (6) are the critical points of the functional :

$\mathrm{F}[\mathrm{N}]=$

$\int_{0}^{T}\left\{\frac{1}{2}\left[\left(\frac{d N(t)}{d t}-\int_{0}^{1} N(t-s) b(s) d s\right)\right]^{2}-\left[(N(t))^{2}\left(\frac{d N(t)}{d t}\right.\right.\right.$

$\left.\left.\left.-\int_{0}^{\infty} N(t-s) b(s)\right) d s\right)\right] ; d t \ldots(7)$

This equation represents the variational formulation of the delay integro-differential equation (7) which is the variational formulation of the model of population growth with delay.[6].

3. Numerical solution of the model of population growth:-

We will take the survival function in (6), which represents the probability of survival of ages, by the following :$b(s)=s^{2}$

Hence:-

$b^{\bullet}(s)=2 s$

Therefore, equation (6) becomes:$\frac{d N(t)}{d t}=(N(t))^{2}+\int_{0}^{\tau} 2 s N(t-s) d s, 0 \leq t \leq \tau$

The critical points of (7) are the same solution of delay integro-differential equation (9).

The critical points of the functional $\mathrm{F}$ could be found by using Hook and Jeeves optimization method that minimizes the functional using the bilinear form :-

$<\mathrm{u}, \mathrm{v}>=\int_{0}^{T} u(t) v(t) d x$

and degree Gaussian quadrature integration method .[8],[9],[10].

By using the direct ritz method, we write the function $\mathrm{N}(\mathrm{t})$ as a linear combination of some basis functions, by letting:-
$\mathrm{N}(\mathrm{t})=a_{o}+a_{1} t+a_{2} t^{2}+a_{3} t^{3} \ldots \ldots .(10)$

Hence :-

$$
\frac{d N}{d t}=a_{1}+2 a_{2} t+3 a_{3} t^{2}
$$

Also,

$N(t-s)=a_{o}+a_{1}(t-s)+$

$a_{2}(t-s)^{2}+a_{3}(t-s)^{3}$..

Substituting (10),(11),(12) backing to the functional (7), We get :-

$$
\begin{aligned}
& F[N]=\int_{0}^{T}\left\{\left[\frac{1}{2}\left(-a_{0}+\frac{5 a_{1}}{3}-\frac{a_{2}}{2}+\frac{2 a_{3}}{5}\right)+\right.\right. \\
& \left.\left(-a_{1}+\frac{10 a_{2}}{3}-\frac{3 a_{3}}{2}\right) t+\left(-a_{2}+5 a_{3}\right) t^{2}-a_{3} t^{3}\right]^{2}- \\
& {\left[\left(a_{0}+a_{1} t+a_{2} t^{2}+a_{3} t^{3}\right)^{2}\right]} \\
& \left(\left(-a_{0}+\frac{5 a_{1}}{3}-\frac{a_{2}}{2}+\frac{2 a_{3}}{5}\right)+\left(-a_{1}+\frac{10 a_{2}}{3}-\frac{3 a_{3}}{2}\right) t+\right. \\
& \left.\left.\left.\left(-a_{2}+5 a_{3}\right) t^{2}-a_{3} t^{3}\right)\right]\right\} d t \ldots \ldots(13)
\end{aligned}
$$

The critical points of (13) could be found using the computer.

Such that suppose that the population size at time $\mathrm{t}=0$ to be equals to $a_{0}=.1$

And carrying out the minimization on $\mathrm{F}[\mathrm{N}]$ using hook and jeeves ptimization method with the initial value for $\mathrm{a} 1, \mathrm{a} 2$ and $\mathrm{a} 3$ to be equals to zero in order to ensure that the population size at time $\mathrm{t}=0$ equals to ao, we have the following results:-

$a_{1}=0.0773, a_{2}=5.29 \times 10^{-3}$,

$a_{3}=-2.7 \times 10^{-2}$

With functional minimum equals to :$-3.570741 \times 10^{-4}$.

\section{References:-}

1-Myer, W.J.1990.Principle of mathematical modeling,translated to Arabic from English by Dr.Habeeb Al-Doory, College of Science,Baghdad University, pp200. 
2-Jerri, A.J., 1985.Introduction to integral equations with applications, Marce Dekker Inc., pp280.

3-Driver, R .D .,1977.Ordinary and Delay differential equations, Springier-verlay,New York,Inc., pp220.

4-Abdul Khaliqe E.Mized,2007. Approximated methods for linear delay differential equations using weighted residual methods ,UmSalama science,Journal,vol.(4):658-665.

5-GoreckSons, 1989. Analysis and Synthesis of time delay system, Pwn-Polish Scientific Publishei, H.,Fuksa S., Grabowski P.,Kory
towski,A.John Wiley and rs ware zawa,pp150.

6-Latiff ,T. A. 2001.About delay integral equationsM.Sc.,Thesis, College of Education Ibn AlHaitham of Baghdad University.

7-Magri, F., 1974.Varation formulation for every linear equation, Int.J.Engny Sci, 12.P.537-49,

8-Bunday, B.D., 1984. Basic Optimiziation Methods, Edward Arnold, pp 250.

9-Burden, R .L and Faires J D., 1985.Numerical Analysis, Third Edition, Pws,pp20.

10-Stroud,A.H., 1966. Gaussian quadrature formula, Prentice-Hall, Inc.,pp175.

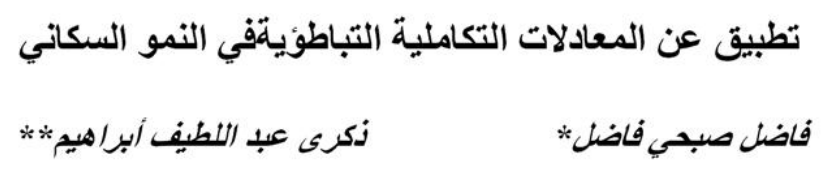

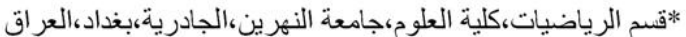

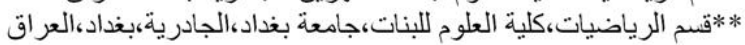

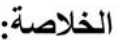

في هذا البحث سوف نصف ،نتاقش وندرس المعادلات التكاملية التباطؤية في النمو السكاني وتحويل هذا النموذج الى معادلة تفاضيلة_تكاملية. وآخبر ا،سوف نحل هذه المسألة بأستخدام طرق حسبان التغاير . 